\title{
AN ANALYTICAL ELASTIC-PLASTIC STRESS ANALYSIS FOR A STEEL FIBRE REINFORCED THERMOPLASTIC COMPOSITE BEAM SUBJECTED TO THERMAL LOADING
}

\author{
Hasan Çallığlu*, Mehmet Şenel ${ }^{* *}$ and Mehmet Savran* \\ * Department of Mechanical Engineering, Dokuz Eylül University, İzmir, Turkey. \\ ** Department of Mechanical Engineering, Dumlupinar University, Kütahya, Turkey.
}

\begin{abstract}
This paper is concerned with a thermal elastic-plastic stress analysis on a steel fibre reinforced thermoplastic matrix composite beam fixed at its to ends. Temperature varying linearly is chosen at the upper and lower surfaces to be zero and $\mathrm{T}_{0}$, respectively. The solution is performed at $0,60,75$ and $90^{\circ}$ orientation angles. Plastic yielding does not occur at 30 and $45^{\circ}$ orientation angles. It is found that the intensity of the residual stress component of $\sigma_{\mathrm{x}}$ and the equivalent plastic strain are maximum at the lower surface of the beam. The intensity of the residual stress is maximum at $0^{\circ}$ orientation angle. The intensity of the equivalent plastic strain is found to be the greatest at $60^{\circ}$ orientation angle.
\end{abstract}

\section{INTRODUCTION}

Thermal stress problems occur in many branches of engineering design and research: Internal combustion engines, jet engines, and the power generation industry including nuclear power stations, pressure vessel and piping welds, etc. Finding engineering materials which satisfy the requirements of strength, rigidity, fracture toughness, resistance to fatigue and environment, acceptable creep rates at the operating temperature, as well as those of cost and density is often one of the main design limitations. Also the thermal efficiency of heat engines depends on the operating temperature.

Timoshenko and Goodier [1] gives elastic solutions of plane, cylindrical and spherical structures. Hellen et al. [2] described one early exercise in thermal stress analysis that compared the result from a finite difference program and two different F.E.M. programs with results from a theoretical elastic solution for a thick spherical shell under axisymmetrically radiated thermal loading. Yeh et al. [3] investigated the mean values of the through-thickness coefficients of hygrothermal expansion in the randomlyoriented laminate.

Because of leading to premature failure, residual stresses in composites are particularly important. Kfouri and Wong [4] compared theoretical and finite element stress analysis solutions for a bimaterial strip and plate under thermal loading. Ho and Saigal [5] investigated thermal residual stresses developed during casting $\mathrm{SiC} / \mathrm{Al}$ particulatereinforced composites. Akay and Özden [6] measured the thermal stresses in injection moulded thermoplastics by removing thin layers from specimens. 
Domb and Hansen [7] developed a numerical model for prediction of the processinduced thermal residual stresses in the thermoplastic composite laminates. Unger and Hansen [8] presented a method which accounts for the effect of process-induced thermal residual stresses on the free-edge delamination behavior of the reinforced laminates, $\left(+35_{2} /-35_{2} / 0_{2} / 90_{2}\right)_{\mathrm{s}}$ graphite-reinforced PEEK.

Jeronimidis and Parkyn [9] found residual stresses in carbon-fiber thermoplastic matrix laminates. Sayman and Kayrici [10] investigated residual stresses in a thermoplastic composite cantilever beam loaded by a single force. Zhou et al. [11] studied mechanical properties and damage evolution of short-fiber-reinforced metal-matrix composites under a micromechanics model accounting for the history of cooling and thermal cycling. Yoon and Kim [12] measured elastic properties and coefficients of the thermal expansion of Carbon/Epoxy laminates in the material principal directions for temperature variation, and characterized as functions of temperature.

In this study, a thermal elastic-plastic stress analysis is carried out on a steel fibre high density polyethylene matrix composite beam. The distribution of residual stress and deformations are found, analytically.

\section{ELASTIC SOLUTION}

A thermoplastic matrix composite beam fixed by two rigid planes is shown in Figure 1. It is assumed that stress components at $0^{\circ} \mathrm{C}$ are zero at the fixed ends and in the beam. The length of the beam is chosen as $120 \mathrm{~mm}$ for preventing buckling of the beam. The governing differential equation for the plane stress case is given as [13],

$\bar{a}_{22} \frac{\partial^{4} F}{\partial x^{4}}-2 \bar{a}_{26} \frac{\partial^{4} F}{\partial x^{3} \partial y}+\left(2 \bar{a}_{12}+\bar{a}_{66}\right) \frac{\partial^{4} F}{\partial x^{2} \partial y^{2}}-2 \bar{a}_{16} \frac{\partial^{4} F}{\partial x \partial y^{3}}+\bar{a}_{11} \frac{\partial^{4} F}{\partial y^{4}}=0$

where $\mathrm{F}$ is a stress function.
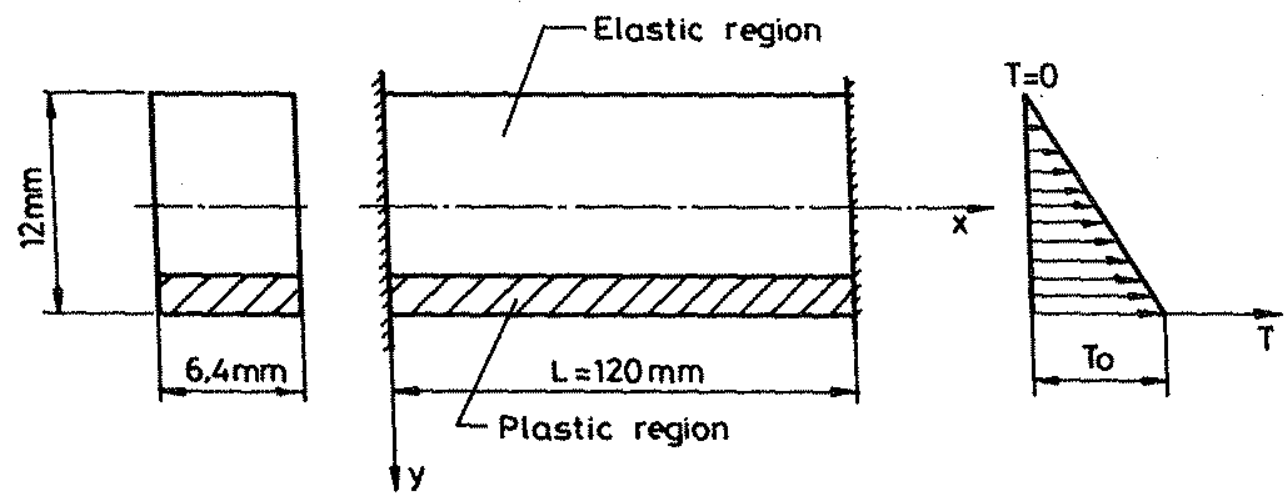

Fig. 1. Thermoplastic composite beam. 
There is corresponding equation for the strain-stress relation [14]

$$
\left|\begin{array}{l}
\varepsilon_{x} \\
\varepsilon_{y} \\
\varepsilon_{x y}
\end{array}\right|=\left[\begin{array}{lll}
\bar{a}_{11} & \bar{a}_{12} & \bar{a}_{16} \\
\bar{a}_{21} & \bar{a}_{22} & \bar{a}_{26} \\
\frac{\bar{a}_{16}}{2} & \frac{\bar{a}_{26}}{2} & \frac{\bar{a}_{66}}{2}
\end{array}\right]\left[\begin{array}{c}
\sigma_{x} \\
\sigma_{y} \\
\tau_{x y}
\end{array}\right]
$$

and $\bar{a}_{i j}$ are the components of the compliance matrix. If thermal expansion coefficients for an orthotropic material are known in the principal material directions, they are obtained in the direction of $\mathrm{x}$ and $\mathrm{y}$ axes as follows [15]

$$
\begin{aligned}
& \alpha_{x}=\alpha_{1} \cos ^{2} \theta+\alpha_{2} \sin ^{2} \theta \\
& \alpha_{y}=\alpha_{1} \sin ^{2} \theta+\alpha_{2} \cos ^{2} \theta \\
& \alpha_{x y}=2\left(\alpha_{1}-\alpha_{2}\right) \sin \theta \cos \theta
\end{aligned}
$$

The boundary conditions for this beam can be written as,

$\sigma_{\mathrm{y}}=0$ at $\mathrm{y}= \pm \mathrm{c}$

$\tau_{\mathrm{xy}}=0$ at $\mathrm{y}= \pm \mathrm{c}$

The stress function $\mathrm{F}=\frac{d}{6} \mathrm{y}^{3}+\frac{e}{2} y^{2}$ is chosen for both satisfying the differential equation and the boundary conditions. The stress components from this stress function are determined as:

$\sigma_{x}=d y+e, \quad \sigma_{y}=0, \quad \tau_{x y}=0$

$\sigma_{y}$ and $\tau_{x y}$ satisfy all the boundary conditions. The strain component in the direction of the $x$ axis is written as,

$$
\varepsilon_{x}=\bar{a}_{11} \sigma_{x}+\alpha_{x} T
$$

where $\mathrm{T}$ is given to be a linear function of $\mathrm{y}$ which is zero and $\mathrm{T}_{0}$ at the upper and lower surfaces, respectively,

$$
T=\frac{T_{0}}{2}\left(1+\frac{y}{c}\right)
$$

$\varepsilon_{\mathrm{x}}$ is zero at the boundaries. Using the boundary conditions at the upper and lower surfaces gives the unknown parameters as,

$$
d=-\frac{\alpha_{x} T_{0}}{2 \bar{a}_{11} c}, e=-\frac{\alpha_{x} T_{0}}{2 \bar{a}_{11}} \text { or } e=d c
$$


$\sigma_{x}$ in the elastic region can be written as,

$$
\sigma_{x}=-\frac{\alpha_{x} T_{0}}{2 \bar{a}_{11} c} y-\frac{\alpha_{x} T_{0}}{2 \bar{a}_{11}}
$$

\subsection{Displacement Components}

Strain components with thermal strains for a plane stress case are written as,

$$
\begin{aligned}
& \varepsilon_{x}=\bar{a}_{11} \sigma_{x}+\alpha_{x} T \\
& \varepsilon_{y}=\bar{a}_{12} \sigma_{x}+\alpha_{y} T \\
& \varepsilon_{x y}=\frac{\bar{a}_{16}}{2} \sigma_{x}+\alpha_{x y} T
\end{aligned}
$$

where $\sigma_{x}$ and $\varepsilon_{x}$ are the same in each section due to the same loading and the same structure of the beam. As a result of this, $\varepsilon_{\mathrm{x}}$ and $\mathrm{u}$ are not function of $\mathrm{x}$

$$
\varepsilon_{x}=\frac{\partial u}{\partial x}=0
$$

integrating it, gives

$$
u=C_{1}(y)
$$

and writing $\varepsilon_{\mathrm{y}}$ gives $\mathrm{v}$

$$
\begin{aligned}
& \varepsilon_{y}=\frac{\partial v}{\partial y}=\bar{a}_{12}(d y+d c)+\frac{\alpha_{y} T_{0}}{2}\left(1+\frac{y}{c}\right) \\
& v=\bar{a}_{12}\left(\frac{d y^{2}}{2}+d c y\right)+\frac{\alpha_{y} T_{0}}{2}\left(y+\frac{y^{2}}{2 c}\right)+C_{2}(x)
\end{aligned}
$$

Putting them in $\varepsilon_{x y}$ and using boundary conditions at the fixed ends $(u=v=0$ at $x=0 ; y=0$ and $\mathrm{x}=\mathrm{L} ; \mathrm{y}=0$ ) results the displacement components as,

$$
\begin{aligned}
& u=\frac{\bar{a}_{16} d y^{2}}{2}+\frac{\alpha_{x y} T_{0}}{2 c} y^{2}+\bar{a}_{16} d c y+\alpha_{x y} T_{0} y \\
& v=\bar{a}_{12}\left(\frac{d y^{2}}{2}+d c y\right)+\alpha_{y}\left(\frac{T_{0}}{2} y+\frac{T_{0}}{4 c} y^{2}\right)
\end{aligned}
$$




\section{ELASTIC-PLASTIC SOLUTION}

The Tsai-Hill theory is used as a yield criterion in this solution. $\mathrm{X}, \mathrm{Y}$ and $\mathrm{Z}$ are the yield points in the first, second and third principal material directions, respectively. $S$ is the yield point for pure shear in the 1-2 plane. The yield criterion for the beam can be written as [14],

$\frac{\sigma_{1}^{2}}{X^{2}}+\frac{\sigma_{2}^{2}}{Y^{2}}-\left(\frac{1}{X^{2}}+\frac{1}{Y^{2}}-\frac{1}{Z^{2}}\right) \sigma_{1} \sigma_{2}+\frac{\tau_{12}{ }^{2}}{S^{2}}=1$

multiplying it by $\mathrm{X}^{2}$ gives the equivalent stress in the first principal material direction as,

$\sigma_{e q}=\bar{\sigma}=\sqrt{\sigma_{1}^{2}-p \sigma_{1} \sigma_{2}+\frac{\sigma_{2}^{2} X^{2}}{Y^{2}}+\frac{\tau_{12}{ }^{2} X^{2}}{S^{2}}}$

where $p=X^{2}\left(\frac{1}{X^{2}}+\frac{1}{Y^{2}}-\frac{1}{Z^{2}}\right)$

In the plastic region, the equations of equilibrium for the plane stress case are written as,

$\frac{\partial \sigma_{x}}{\partial x}+\frac{\partial \tau_{x y}}{\partial y}=0$
$\frac{\partial \tau_{x y}}{\partial x}+\frac{\partial \sigma_{y}}{\partial y}=0$

$\sigma_{\mathrm{y}}$ and $\tau_{\mathrm{xy}}$ are both zero and those satisfy the second equation. From the first equation $\sigma_{x}$ is obtained as $\mathrm{C}(\mathrm{y})$. Subsequently, it is seen that at any section $\sigma_{x}$ is a function of $\mathrm{y}$. For a linear strain-hardening material, the yield stress is given by the Ludwik equation as,

$\sigma_{Y}=\sigma_{o}+K \varepsilon_{p}$

where $\sigma_{0}$ is equal to $\mathrm{X}$ which is the yield point in the first principal material direction, $\mathrm{K}$ and $\varepsilon_{\mathrm{p}}$ are the plasticity constant and the equivalent plastic strain, respectively. The stress components in the principal material directions are obtained by using the transformation formula as

$\sigma_{1}=\sigma_{x} \cos ^{2} \theta, \sigma_{2}=\sigma_{x} \sin ^{2} \theta, \tau_{12}=-\sigma_{x} \cos \theta \sin \theta$

Putting them into Eq.(17) gives the yield point for the orientation angle $\theta$,

$$
X_{1}=\frac{\sigma_{0}}{\mathrm{~N}}=\frac{X}{\mathrm{~N}}
$$


where,

$$
\mathrm{N}=\sqrt{\cos ^{4} \theta-p \sin ^{2} \theta \cos ^{2} \theta+\frac{X^{2} \sin ^{4} \theta}{Y^{2}}+\frac{X^{2} \sin ^{2} \theta \cos ^{2} \theta}{S^{2}}}
$$

The strain increments in the principal material directions can be found by using the potential function $f=\bar{\sigma}-\sigma_{\chi}\left(\varepsilon_{p}\right)[16]$ as,

$$
\left\{\begin{array}{l}
d \varepsilon_{1}^{p} \\
d \varepsilon_{2}^{p} \\
d \varepsilon_{12}^{p}
\end{array}\right\}=\left\{\begin{array}{l}
\frac{\partial f}{\partial \sigma_{1}} d \lambda \\
\frac{\partial f}{\partial \sigma_{2}} d \lambda \\
\frac{\partial f}{\partial \tau_{12}} d \lambda
\end{array}\right\}
$$

The total strain increments in the principal material directions are written as,

$$
\begin{aligned}
& d \varepsilon_{1}=d \varepsilon_{1}^{e}+d \varepsilon_{1}^{p}=a_{11} d \sigma_{1}+a_{12} d \sigma_{2}+\frac{2 \sigma_{1}-p \sigma_{2}}{2 \sigma_{Y}} d \lambda+\alpha_{1} d T \\
& d \varepsilon_{2}=d \varepsilon_{2}^{e}+d \varepsilon_{2}^{p}=a_{12} d \sigma_{1}+a_{22} d \sigma_{2}+\frac{-p \sigma_{1}+\frac{2 \sigma_{2} X^{2}}{Y^{2}}}{2 \sigma_{Y}} d \lambda+\alpha_{2} d T \\
& d \varepsilon_{12}=d \varepsilon_{12}^{e}+d \varepsilon_{12}^{p}=\frac{a_{66} d \tau_{12}}{2}+\frac{2 \tau_{12} \frac{X^{2}}{S^{2}}}{2 \sigma_{Y}} d \lambda
\end{aligned}
$$

where $d \lambda=d \varepsilon_{p}$. For the orientation angle $\theta$, the stress component $\sigma_{\mathrm{x}}$ can be written as

$$
\sigma_{x}=\frac{\sigma_{Y}}{\mathrm{~N}}=\frac{\sigma_{0}+K \varepsilon_{p}}{N}
$$

Substituting $\sigma_{1}, \sigma_{2}$ and $\tau_{12}$ into Eq. (24) and integrating them gives the total strain components as,

$$
\begin{aligned}
& \varepsilon_{1}=a_{11} \sigma_{1}+a_{12} \sigma_{2}+\frac{2 \cos ^{2} \theta-p \sin ^{2} \theta}{2 \mathrm{~N}} \varepsilon_{p}+\alpha_{1} T+C_{5} \\
& \varepsilon_{2}=a_{12} \sigma_{1}+a_{22} \sigma_{2}+\frac{-p \cos ^{2} \theta+2 \sin ^{2} \theta \frac{X^{2}}{Y^{2}}}{2 \mathrm{~N}} \varepsilon_{p}+\alpha_{2} T+C_{6}
\end{aligned}
$$


$\varepsilon_{12}=\frac{a_{66}}{2} \tau_{12}-\frac{2 \sin \theta \cos \theta \frac{X^{2}}{S^{2}}}{2 \mathrm{~N}} \varepsilon_{p}+C_{7}$

By using the boundary conditions on boundary of the elastic and plastic regions and writing $\varepsilon_{\mathrm{p}}=0$ give the integration constants as,

$\left.C_{5}=X_{1} \mid\left(\bar{a}_{11}-a_{11}\right) \cos ^{2} \theta+\left(\bar{a}_{12}-a_{12}\right) \sin ^{2} \theta+\bar{a}_{16} \sin \theta \cos \theta\right\rfloor$

$C_{6}=X_{1}\left[\left(\bar{a}_{11}-a_{22}\right) \sin ^{2} \theta+\left(\bar{a}_{12}-a_{12}\right) \cos ^{2} \theta-\bar{a}_{16} \sin \theta \cos \theta\right]$

$C_{7}=X_{1}\left[\left(\bar{a}_{12}-\bar{a}_{11}\right) \sin \theta \cos \theta+\frac{\bar{a}_{16}}{2} \cos 2 \theta+\frac{a_{66}}{2} \sin \theta \cos \theta\right]$

The strain components in the direction of $\mathrm{x}$ and $\mathrm{y}$ are obtained by using the transformation formula as,

$$
\left\{\begin{array}{l}
\varepsilon_{x} \\
\varepsilon_{y} \\
\varepsilon_{x y}
\end{array}\right\}=\left[\begin{array}{ccc}
\cos ^{2} \theta & \sin ^{2} \theta & -2 \sin \theta \cos \theta \\
\sin ^{2} \theta & \cos ^{2} \theta & 2 \sin \theta \cos \theta \\
\sin \theta \cos \theta & -\sin \theta \cos \theta & \cos ^{2} \theta-\sin ^{2} \theta
\end{array}\right]\left\{\begin{array}{l}
\varepsilon_{1} \\
\varepsilon_{2} \\
\varepsilon_{12}
\end{array}\right\}
$$

By using this matrix, the strain components in the plastic region can be written,

$$
\begin{aligned}
& \varepsilon_{x}=\bar{a}_{11} \sigma_{x}+B_{1} \varepsilon_{p}+\alpha_{x} T \\
& \varepsilon_{y}=\bar{a}_{12} \sigma_{x}+B_{2} \varepsilon_{p}+\alpha_{y} T \\
& \varepsilon_{x y}=\frac{\bar{a}_{16}}{2} \sigma_{x}+B_{3} \varepsilon_{p}+\alpha_{x y} T
\end{aligned}
$$

where

$$
\begin{aligned}
& B_{1}=\frac{2 \cos ^{4} \theta-2 p \cos ^{2} \theta \sin ^{2} \theta+2 \sin ^{4} \theta \frac{X^{2}}{Y^{2}}+4 \sin ^{2} \theta \cos ^{2} \theta \frac{X^{2}}{S^{2}}}{2 \mathrm{~N}} \\
& B_{2}=\frac{2 \cos ^{2} \theta \sin ^{2} \theta-p \sin ^{4} \theta-p \cos ^{4} \theta+2 \sin ^{2} \theta \cos ^{2} \theta \frac{X^{2}}{Y^{2}}-4 \sin ^{2} \theta \cos ^{2} \theta \frac{X^{2}}{S^{2}}}{2 \mathrm{~N}} \\
& B_{3}=\frac{(p+2) \cos ^{3} \theta \sin \theta-p \sin ^{3} \theta \cos \theta-2 \sin ^{3} \theta \cos \theta \frac{X^{2}}{Y^{2}}+\left(-2 \cos ^{3} \theta \sin \theta+2 \sin ^{3} \theta \cos \theta\right) \frac{X^{2}}{S^{2}}}{2 \mathrm{~N}}
\end{aligned}
$$

Writing $\sigma_{\mathrm{x}}=-\mathrm{X}_{1}$ and $\varepsilon_{\mathrm{p}}=0$ at the boundary of the elastic and plastic regions give the expansion of the plastic region (h) as, 
$h=\frac{2 \bar{a}_{11} c}{\alpha_{x} T_{0}}\left(X_{1}-\frac{\alpha_{x} T_{0}}{2 \bar{a}_{11}}\right)$

\subsection{Displacement Components}

The stress components and the displacement are the same at each section of the beam due to the same loading and the same structure of the beam. Subsequently $\varepsilon_{\mathrm{x}}$ is obtained as zero at any point in the beam. At the lower side of the beam, $\sigma_{x}$ is negative. By using these relations, $\varepsilon_{\mathrm{p}}$ is determined as,

$\varepsilon_{x}=\frac{\partial u}{\partial x}=\sigma_{x} \bar{a}_{11}+B_{1} \varepsilon_{p}+\alpha_{x} T$

or

$\varepsilon_{x}=-\frac{\sigma_{0}+K \varepsilon_{p}}{N} \bar{a}_{11}+B_{1} \varepsilon_{p}+\alpha_{x} \frac{T_{0}}{2}\left(1+\frac{y}{c}\right)=0$

$\varepsilon_{p}=a+b y$

where

$a=\frac{2 \bar{a}_{11} \sigma_{0}-\alpha_{x} T_{0} N}{2\left(-\bar{a}_{11} K+B_{1} N\right)}, \quad b=\frac{-\alpha_{x} T_{0} N}{2 c\left(-\bar{a}_{11} K+B_{1} N\right)}$.

Displacement components are obtained as,

$\varepsilon_{x}=\frac{\partial u}{\partial x}=0$, after integration $\mathrm{u}$ is found as, $\mathrm{u}=\mathrm{C}_{8}(\mathrm{y})$

$\varepsilon_{y}=\frac{\partial v}{\partial y}=\bar{a}_{12} \sigma_{x}+B_{2} \varepsilon_{p}+\alpha_{y} T$

$v=-\frac{\bar{a}_{12} \sigma_{0}}{N} y+\left(-\frac{\bar{a}_{12} K}{N}+B_{2}\right)\left(a y+\frac{b y^{2}}{2}\right)+\frac{\alpha_{y} T_{0} y}{2}+\frac{\alpha_{y} T_{0} y^{2}}{4}+C_{9}(x)$

and putting $\mathrm{u}$ and $\mathrm{v}$ in the relation of $\varepsilon_{\mathrm{xy}}$ gives the following displacement components:

$$
\begin{aligned}
& u=-\frac{\bar{a}_{16} \sigma_{0}}{N} y+\left(-\frac{\bar{a}_{16} K}{N}+2 B_{3}\right)\left(a y+\frac{b y^{2}}{2}\right)+\frac{\alpha_{x y} T_{0} y^{2}}{2 c}+\alpha_{x y} T_{0} y+C_{11} \\
& \nu=-\frac{\bar{a}_{12} \sigma_{0}}{N} y+\left(-\frac{\bar{a}_{12} K}{N}+B_{2}\right)\left(a y+\frac{b y^{2}}{2}\right)+\frac{\alpha_{y} T_{0} y^{2}}{4 c}+\frac{\alpha_{x y} T_{0}}{2} y+C_{10}
\end{aligned}
$$

The displacement components on the boundary of the elastic and plastic regions are equal. At the lower side of the beam, they can be written as 
$u_{e}=u_{p}, v_{e}=v_{p}$ and $\left(\frac{\partial v}{\partial x}\right)_{e}=\left(\frac{\partial v}{\partial x}\right)_{p}$ at $(\mathrm{x}=0, \mathrm{y}=\mathrm{h})$ and $(\mathrm{x}=\mathrm{l}, \mathrm{y}=\mathrm{h})$

By using these conditions, they are obtained as,

$$
\begin{array}{r}
\begin{array}{r}
u=-\frac{\bar{a}_{16} \sigma_{0}}{N} y+\left(-\frac{\bar{a}_{16} K}{N}+2 B_{3}\right)\left(a y+\frac{b y^{2}}{2}\right)+ \\
+\left(-\frac{\alpha_{x y} T_{0} y^{2}}{2 c}+\alpha_{x y} T_{0} y+\frac{\bar{a}_{16} d h^{2}}{2}+\frac{\bar{a}_{16} \sigma_{0}}{N} h\right. \\
\left.\begin{array}{r}
v=-\frac{\bar{a}_{12} \sigma_{0}}{N} y+\left(-\frac{\bar{a}_{12} K}{N}+B_{2}\right)\left(a h+\frac{b h^{2}}{2}\right)+\bar{a}_{16} d c h \\
2
\end{array}\right)+\frac{\alpha_{y} T_{0} y^{2}}{4 c}+\frac{\alpha_{y} T_{0}}{2} y+\bar{a}_{12}\left(\frac{d h^{2}}{2}+d c h\right) \\
-\left(-\frac{\bar{a}_{12} K}{N}+B_{2}\right)\left(a h+\frac{b h^{2}}{2}\right)+\frac{\bar{a}_{12} \sigma_{0}}{N} h
\end{array}
\end{array}
$$

\section{RESIDUAL STRESS COMPONENT}

In the previous section, the elastic-plastic solution is obtained. To find the residual stresses it is necessary to superpose on the stress system in the elastic-plastic solution a completely elastic system due to the same external forces applied in the opposite directions. The resultants of the stresses at the fixed ends for the elastic and plastic regions are $F_{1}$ and $F_{2}$, respectively. If $F_{1}$ and $F_{2}$ are reduced to the middle axis of the beam, they produce a force $F=F_{1}+F_{2}$ and a bending moment $M=M_{1}+M_{2}$ as shown in Figure 2. The elastic stress component of $\sigma_{\mathrm{x}}$ according to the Saint-Venant's principle can be obtained under the external forces of $-\mathrm{F}$ and $-\mathrm{M}$. The axial force and the bending moment are obtained as,

$$
\begin{aligned}
& \mathrm{F}=\mathrm{F}_{1}+\mathrm{F}_{2}=\frac{\mathrm{X}_{1} \mathrm{t}(\mathrm{c}+\mathrm{h})}{2}+\frac{t\left(\sigma_{0}+K a\right)(c-h)}{N}+\frac{K b t\left(c^{2}-h^{2}\right)}{2 N} \\
& \mathrm{M}=\mathrm{M}_{1}+\mathrm{M}_{2}=\frac{\mathrm{X}_{1} \mathrm{t}(\mathrm{c}+\mathrm{h})(2 \mathrm{~h}-\mathrm{c})}{6}+\frac{t\left(\sigma_{0}+K a\right)}{N}\left(c^{2}-h^{2}\right)+\frac{K b t}{3 N}\left(c^{3}-h^{3}\right)
\end{aligned}
$$

where $t$ is the thickness of the beam.

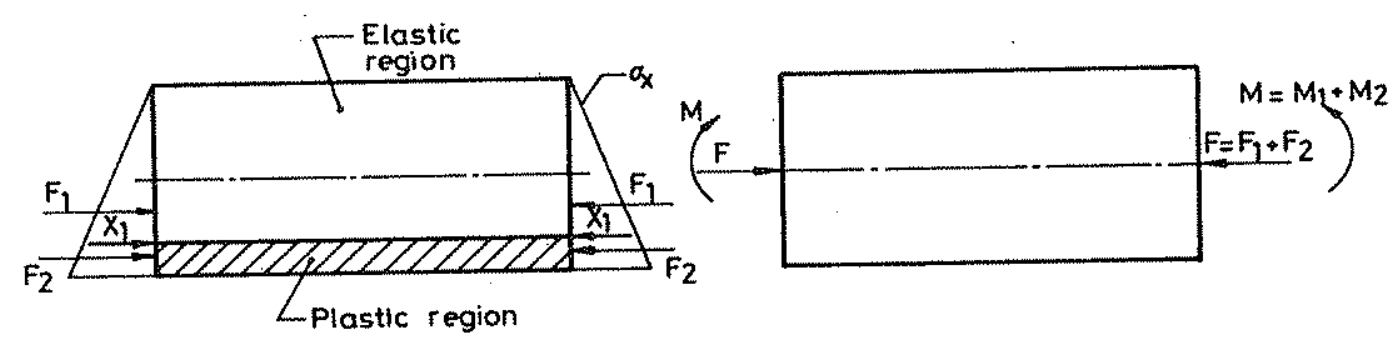

Fig. 2. External forces for the elastic solution. 
The stress component $\sigma_{\mathrm{x}}$ can be written as,

$\sigma_{x}=-\frac{F}{2 c t}-\frac{M y}{I}$

where $I$ is the inertia moment of the cross section of the beam.

\section{A SAMPLE AND DISCUSSION}

A steel fibre reinforced thermoplastic matrix composite beam is used for the analytical solution. Its mechanical properties and yield strengths are given in Table 1. The stress component of $\sigma_{\mathrm{x}}$ is compressive in the beam. Plastic yielding begins at the lower surface of the beam. If the beam is fixed to the rigid planes at the $0{ }^{\circ} \mathrm{C}$ without any stress, the temperature $\left(T_{0}\right)$ causing plastic yielding of the beam at the lower surface is given in Table 2. As seen from this Table, It is maximum at $60^{\circ}$ orientation angle as $77.48{ }^{\circ} \mathrm{C}$. It is $69.55^{\circ} \mathrm{C}$ at the $0^{\circ}$ orientation angle. The temperature starting plastic yielding depends on the stiffness and the yield point of the beam.

Table 1. Mechanical properties and yield strengths of the composite beam.

\begin{tabular}{|c|c|c|c|c|c|}
\hline $\begin{array}{c}\mathrm{E}_{1} \\
\mathrm{MPa}\end{array}$ & $\begin{array}{c}\mathrm{E}_{2} \\
\mathrm{MPa}\end{array}$ & $\begin{array}{c}\mathrm{G}_{12} \\
\mathrm{MPa}\end{array}$ & $v_{12}$ & $\begin{array}{c}\mathrm{X} \\
\mathrm{MPa}\end{array}$ & $\begin{array}{c}\mathrm{Y} \\
\mathrm{MPa}\end{array}$ \\
\hline 38000 & 1300 & 360 & 0.25 & 37 & 5 \\
\hline
\end{tabular}

\begin{tabular}{|c|c|c|c|c|c|}
\hline $\begin{array}{c}\mathrm{Z} \\
\mathrm{MPa}\end{array}$ & $\begin{array}{c}\mathrm{S} \\
\mathrm{MPa}\end{array}$ & $\underset{\mathrm{MPa}}{\mathrm{K}}$ & $\begin{array}{c}\alpha_{1} \\
1 / 0 \mathrm{C}\end{array}$ & $\begin{array}{c}\alpha_{2} \\
1 /{ }^{\circ} \mathrm{C}\end{array}$ & $\begin{array}{c}\text { Melting } \\
\text { Point }\end{array}$ \\
\hline 16 & 13 & 99 & 14. $10^{-6}$ & $122.10^{-6}$ & $190^{\circ} \mathrm{C}$ \\
\hline
\end{tabular}

Table 2. Temperature starting plastic yielding in the beam and yield strength of the beam.

\begin{tabular}{|c|c|c|c|c|}
\hline$\theta$ & $0^{\circ}$ & $60^{\circ}$ & $75^{\circ}$ & $90^{\circ}$ \\
\hline $\mathrm{T}_{0}\left({ }^{\circ} \mathrm{C}\right)$ & 69.55 & 77.48 & 40.48 & 31.52 \\
\hline $\mathrm{X}_{1}(\mathrm{MPa})$ & 37.00 & 7.72 & 5.51 & 5.00 \\
\hline
\end{tabular}

Elastic-plastic, elastic and residual stress components of $\sigma_{\mathrm{x}}$ are given in Table 3. It is seen that the residual stress components of $\sigma_{\mathrm{x}}$ is maximum at the lower surface. It is positive at the lower and upper surfaces. The residual stress component of $\sigma_{x}$ is the greatest at the $0^{\circ}$ orientation angle and $h=1 \mathrm{~mm}$ as $8.88 \mathrm{MPa}$. If the orientation angle is increased it becomes smaller. The residual stress component at the lower surface is greater than that at the upper surface.

The displacement components in the elastic and plastic regions and equivalent plastic strain are given in Table 4. As seen from this Table, the displacement components are not large in the beam. The intensity of the axial and transverse displacements at the lower surface are maximum at 75 and $60^{\circ}$ orientation angles $(\mathrm{h}=1 \mathrm{~mm})$ as $682.010^{-4}$ and 
$-1728.310^{-4} \mathrm{~mm}$, respectively. The intensity of the equivalent plastic strain at the lower surface is maximum at $60^{\circ}$ orientation angle $(\mathrm{h}=1 \mathrm{~mm})$ as $-10.310^{-4}$. It is $-710^{-4},-4.9$ $10^{-4}$ and $-3.710^{-4}$ at 0,75 and $90^{\circ}$ orientation angles $(\mathrm{h}=1 \mathrm{~mm})$, respectively.

Table 3. Elastic, elastic-plastic and residual stress components at the upper and lower surfaces of the beam.

\begin{tabular}{|c|c|c|c|c|c|c|c|c|}
\hline \multirow[b]{2}{*}{$\theta$} & \multirow[b]{2}{*}{$\begin{array}{c}\mathrm{T}_{0} \\
\left({ }^{\circ} \mathrm{C}\right)\end{array}$} & \multirow[b]{2}{*}{$\begin{array}{c}\mathrm{H} \\
(\mathrm{mm})\end{array}$} & \multicolumn{3}{|c|}{ At the lower surface } & \multicolumn{3}{|c|}{ At the upper surface } \\
\hline & & & $\begin{array}{c}\left(\sigma_{\mathrm{x}}\right)_{\mathrm{p}} \\
(\mathrm{MPa})\end{array}$ & $\begin{array}{c}\left(\sigma_{\mathrm{x}}\right)_{\mathrm{e}} \\
(\mathrm{MPa})\end{array}$ & $\begin{array}{c}\left(\sigma_{\mathrm{x}}\right)_{\mathrm{r}} \\
(\mathrm{MPa})\end{array}$ & $\begin{array}{c}\left(\sigma_{\mathrm{x}}\right)_{\mathrm{p}} \\
(\mathrm{MPa})\end{array}$ & $\begin{array}{c}\left(\sigma_{x}\right)_{\mathrm{e}} \\
(\mathrm{MPa})\end{array}$ & $\begin{array}{c}\left(\sigma_{\mathrm{x}}\right)_{\mathrm{r}} \\
(\mathrm{MPa})\end{array}$ \\
\hline \multirow{5}{*}{$0^{\circ}$} & 75.87 & 5 & -37.01 & 39.83 & 2.82 & 0 & 0.26 & 0.26 \\
\hline & 83.46 & 4 & -37.02 & 42.13 & 5.11 & 0 & 1.03 & 1.03 \\
\hline & 92.73 & 3 & -37.03 & 43.92 & 6.89 & 0 & 2.32 & 2.32 \\
\hline & 104.32 & 2 & -37.05 & 45.20 & 8.15 & 0 & 4.12 & 4.12 \\
\hline & 119.23 & 1 & -37.07 & 45.95 & 8.88 & 0 & 6.44 & 6.44 \\
\hline \multirow{5}{*}{$60^{\circ}$} & 84.53 & 5 & -7.73 & 8.24 & 0.51 & 0 & 0.13 & 0.13 \\
\hline & 92.98 & 4 & -7.73 & 8.66 & 0.93 & 0 & 0.35 & 0.35 \\
\hline & 103.31 & 3 & -7.74 & 8.98 & 1.24 & 0 & 0.67 & 0.67 \\
\hline & 116.23 & 2 & -7.74 & 9.20 & 1.46 & 0 & 1.10 & 1.10 \\
\hline & 132.83 & 1 & -7.75 & 9.31 & 1.56 & 0 & 1.62 & 1.62 \\
\hline \multirow{5}{*}{$75^{\circ}$} & 44.16 & 5 & -5.51 & 5.88 & 0.37 & 0 & 0.09 & 0.09 \\
\hline & 48.57 & 4 & -5.52 & 6.19 & 0.67 & 0 & 0.25 & 0.25 \\
\hline & 53.97 & 3 & -5.52 & 6.42 & 0.90 & 0 & 0.48 & 0.48 \\
\hline & 60.72 & 2 & -5.52 & 6.58 & 1.06 & 0 & 0.78 & 0.78 \\
\hline & 69.39 & 1 & -5.52 & 6.66 & 1.14 & 0 & 1.15 & 1.15 \\
\hline \multirow{5}{*}{$90^{\circ}$} & 34.39 & 5 & -5.00 & 5.34 & 0.34 & 0 & 0.08 & 0.08 \\
\hline & 37.83 & 4 & -5.00 & 5.61 & 0.61 & 0 & 0.22 & 0.22 \\
\hline & 42.03 & 3 & -5.00 & 5.83 & 0.83 & 0 & 0.42 & 0.42 \\
\hline & 47.29 & 2 & -5.00 & 5.97 & 0.97 & 0 & 0.69 & 0.69 \\
\hline & 54.04 & 1 & -5.00 & 6.05 & 1.05 & 0 & 1.03 & 1.03 \\
\hline
\end{tabular}

The distribution of the residual stress component of $\sigma_{x}$ along the sections of the beam at the $0^{\circ}$ orientation angle is shown in Figure 3. As seen from this Figure the intensity of the residual stress component of $\sigma_{x}$ is maximum at the lower surface. It is 8.88 and 6.44 $\mathrm{MPa}$ at the lower and upper surfaces, respectively.

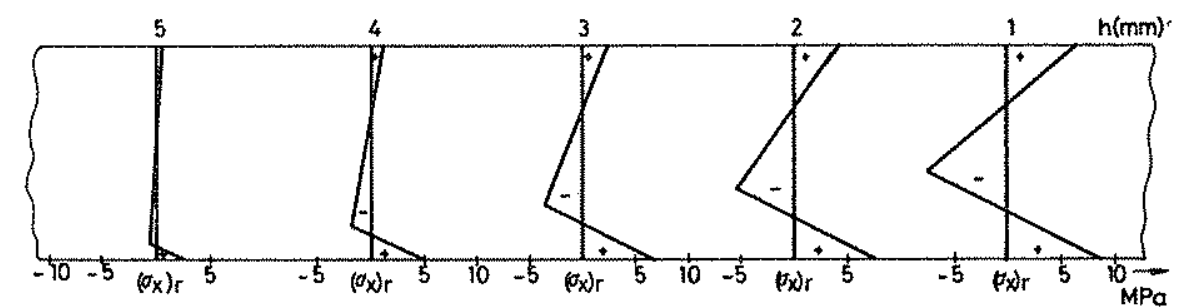

Fig. 3. The distribution of the residual stress component $\sigma_{\mathrm{x}}$ at the $0^{\circ}$ orientation angle.

The distribution of the residual stress component of $\sigma_{x}$ along the sections of the beam at 60,75 and $90^{\circ}$ orientation angles is shown in Figure 4,5 and 6. As seen from these Figures, when the orientation angle is increased the intensity of the residual stress component becomes smaller. It is the smallest at the $90^{\circ}$ orientation angle per $\mathrm{h}$. 
When the plastic region is increased further, the intensity of residual stress component of $\sigma_{x}$ becomes greater.

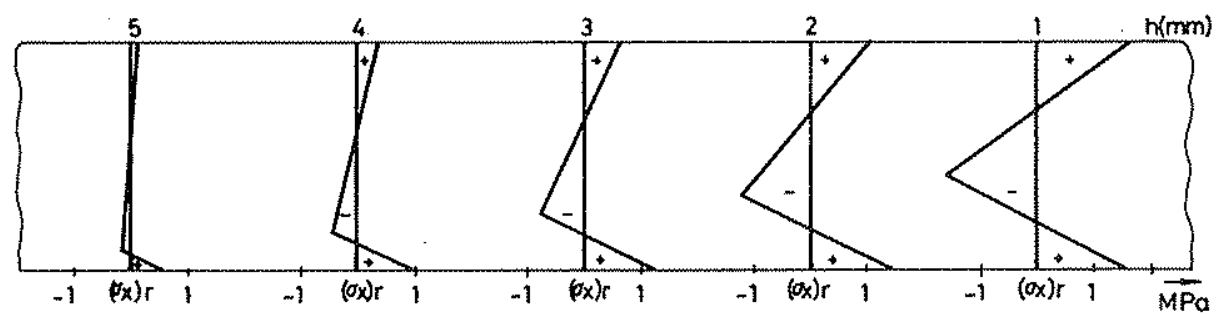

Fig. 4. The distribution of the residual stress component $\sigma_{x}$ at the $60^{\circ}$ orientation angle.

Table 4. Displacement components and equivalent plastic strain in the beam.

\begin{tabular}{|c|c|c|c|c|c|c|}
\hline \multirow[t]{2}{*}{$\theta$} & \multirow{2}{*}{$\begin{array}{c}\mathrm{h} \\
(\mathrm{mm})\end{array}$} & \multirow{2}{*}{$\begin{array}{c}\varepsilon_{\mathrm{p}}\left(10^{-4}\right) \\
\text { At the lower } \\
\text { surface }\end{array}$} & \multicolumn{2}{|c|}{$\begin{array}{l}\text { At the elastic-plastic } \\
\text { boundary }(x ; y=h)\end{array}$} & \multicolumn{2}{|c|}{$\begin{array}{l}\text { At the lower surface } \\
\qquad(x ; y=c)\end{array}$} \\
\hline & & & $\begin{array}{c}\mathrm{u}_{\mathrm{e} .}\left(10^{-4}\right) \\
(\mathrm{mm})\end{array}$ & $\begin{array}{l}\mathrm{v}_{\mathrm{e}}\left(10^{-4}\right) \\
(\mathrm{mm})\end{array}$ & $\begin{array}{l}\mathrm{u}_{\mathrm{p}}\left(10^{-4}\right) \\
(\mathrm{mm})\end{array}$ & $\begin{array}{l}\mathrm{v}_{\mathrm{p}}\left(10^{-4}\right) \\
(\mathrm{mm})\end{array}$ \\
\hline \multirow{5}{*}{$0^{\circ}$} & 5 & -0.9 & 0.0 & 307.1 & 0.0 & 287.9 \\
\hline & 4 & -2.0 & 0.0 & 252.0 & 0.0 & 184.6 \\
\hline & 3 & -3.3 & 0.0 & 193.9 & 0.0 & 48.0 \\
\hline & 2 & -4.9 & 0.0 & 131.4 & 0.0 & -173.0 \\
\hline & 1 & -7.0 & 0.0 & 63.0 & 0.0 & -504.2 \\
\hline \multirow{5}{*}{$60^{\circ}$} & 5 & -1.3 & -491.3 & -124.1 & -470.5 & -221.0 \\
\hline & 4 & -2.9 & -399.2 & -130.6 & -364.4 & -353.4 \\
\hline & 3 & -4.8 & -301.7 & -138.3 & -257.2 & -542.9 \\
\hline & 2 & -7.2 & -197.1 & -147.6 & -132.3 & -869.6 \\
\hline & 1 & -10.3 & -82.0 & -159.2 & 111.5 & -1728.3 \\
\hline \multirow{5}{*}{$75^{\circ}$} & 5 & -0.6 & -56.1 & -27.6 & -13.9 & -52.1 \\
\hline & 4 & -1.4 & -33.8 & -29.7 & 59.0 & -87.3 \\
\hline & 3 & -2.3 & -9.8 & -32.1 & 152.4 & -138.6 \\
\hline & 2 & -3.4 & 16.4 & -35.0 & 301.1 & -226.6 \\
\hline & 1 & -4.9 & 45.6 & -38.5 & 682.0 & -449.5 \\
\hline \multirow{5}{*}{$90^{\circ}$} & 5 & -0.5 & 0.0 & 14.3 & 0.0 & 12.4 \\
\hline & 4 & -1.0 & 0.0 & 11.5 & 0.0 & 5.5 \\
\hline & 3 & -1.7 & 0.0 & 8.6 & 0.0 & -4.7 \\
\hline & 2 & -2.6 & 0.0 & 5.4 & 0.0 & -20.2 \\
\hline & 1 & -3.7 & 0.0 & 2.0 & 0.0 & -47.0 \\
\hline
\end{tabular}

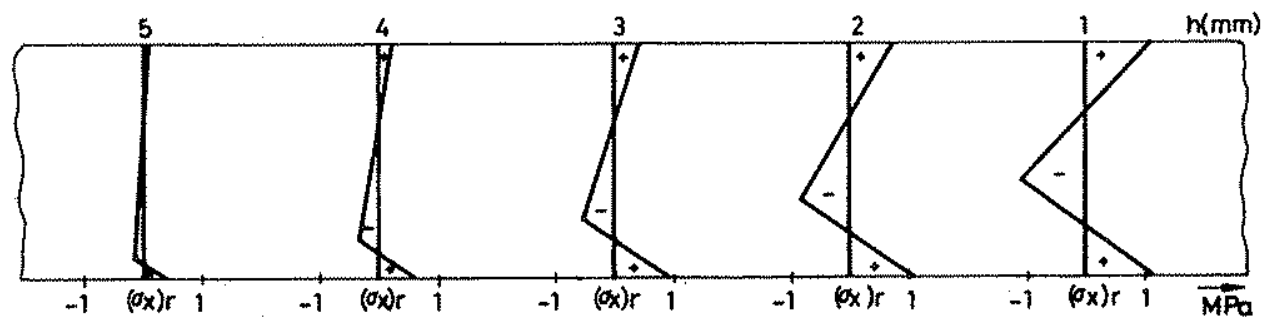

Fig. 5. The distribution of the residual stress component $\sigma_{x}$ at the $75^{\circ}$ orientation angle. 


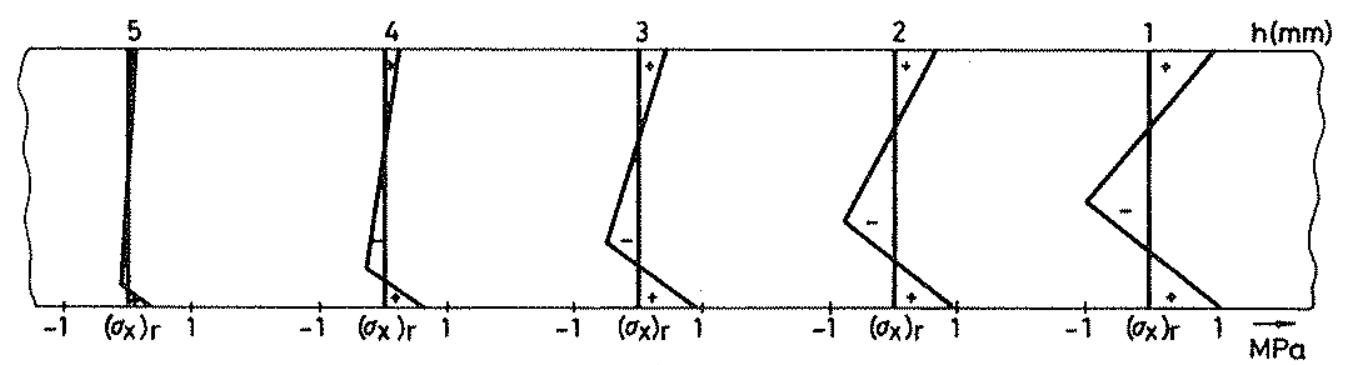

Fig. 6. The distribution of the residual stress component $\sigma_{\mathrm{x}}$ at the $90^{\circ}$ orientation angle:

\section{CONCLUSION}

The following conclusions are deduced from the elastic-plastic thermal behavior of the beam:

1) Thermal stresses are important in the design because they lead to plastic yielding or failure of the material.

2) When material stiffness is increased, it produces higher residual stresses.

3) The intensity of the residual stress component of $\sigma_{x}$ assumes a maximum at the lower surface, and its greatest value is at the $0^{\circ}$ orientation angle.

4) The intensity of the equivalent plastic strain is found to be maximum at the $60^{\circ}$ orientation angle.

5) Plastic yielding does not occur for all the orientation angles. For instance, it is determined that 30 and $45^{\circ}$ orientation angles do not have a plastic yielding.

\section{REFERENCES}

1. S. P. Timoshenko and J. N. Goodier, Theory of Elasticity, $3^{\text {rd }}$ ed. McGraw-Hill, New York, 1970.

2. T. K. Hellen, N. G. Galuzzo and A. P. Kfouri, The elastic-plastic analysis of a thick spherical shell under thermal loading-a comparison of three numerical procedures, Int. J. Mech. Sci. Pergamon Press, 19, 209-221, 1977.

3. H. L. Yeh and H. Y. Yeh, The variation in though-thickness hygrothermal expansion coefficients of laminate composites, J. Compo. Mater. 34(14), 1200$1215,2000$.

4. A. P. Kfouri and H. D. Wong, Comparison of theoretical and finite element stress analysis solutions for a bimaterial strip and plate subjected to thermal loading, Fatigue Fract. Engng Mater. Struct. 16(12), 1381-1395, 1993.

5. S. Ho and A. Saigal, Three dimensional modeling of thermal residual stresses and mechanical behavior of cast SiC/Al particulate composites, Acta Metall. Mater. 42(10), 3253-3262, 1994.

6. M. Akay and S. Özden, Measurement of residual stresses in injection moulded thermoplastics, Polymer Testing, 13, 323-354, 1994.

7. M. Domb and J. S. Hansen, The effect of cooling rate an free-edge stress development in semi-crystalline thermoplastic laminate, J. Compo. Mater. 32(4), 361-385, 1998. 
8. W. J. Unger and J. S. Hansen, A method to predict the effect of thermal residual stresses on the free-edge delamination behavior of fibre reinforced composite laminates, J. Compo. Mater. 32(5), 431-459, 1998.

9. G. Jeronimidis and A. T. Parkyn, Residual stress in carbon fibre-thermoplastic matrix laminates, J. Comp. Mater. 22(5), 401-415, 1998.

10. O. Sayman and M. Kayrici, An elastic-plastic stress analysis in a thermoplastic composite cantilever beam, Compo. Sci. Techn. 60, 623-631, 2000.

11. C. Zhou, W. Yang and D. Fang, Damage of short-fiber-reinforced metal matrix composites considering cooling and thermal cycling, J. Engng. Mater. Techn. 122, 203-208, 2000.

12. K. J. Yoon and J. S. Kim, Prediction of thermal expansion properties of carbon/epoxy laminates for temperature variation, J. Compo. Mater. 34(2), 90$100,2000$.

13. S. G. Lekhnitskii, Anisotropic Plates, Gordon and Breach, New York, 1968.

14. R. M. Jones, Mechanics of Composite Materials, Mc Graw-Hill Kogakusha, Tokyo, 1975.

15. D. Hull, An Introduction to Composite Materials, University Press, Cambridge, 1987.

16. D. R. J. Owen and E. Hinton, Finite Elements in Plasticity, Pineridge, Swansea, 1980. 